\title{
COMPROMISSO POLÍTICO E COMPETÊNCIA TÉCNICA: 20 ANOS DEPOIS
}

\author{
Paolo Nosella
}

RESUMO: Este artigo faz uma releitura do debate ocorrido na década de 1980 a respeito da relação entre o compromisso político e a competência técnica do educador. Pontua que as idéias mais emancipadas (como as propaladas pelos textos de Antônio Gramsci) fizeram com que o pensamento pedagógico assumisse no Brasil sua dimensão de engajamento político, contribuindo, inclusive, para as vitórias eleitorais do Partido dos Trabalhadores. Entretanto, se naquela época certo "modismo gramsciniano" foi referência e sinônimo de idéias mais emancipadas e arejadas, hoje, diante da realidade política, complexa e multifacetada, torna-se necessário aprofundar a leitura dos textos desse autor. Uma difusa ideologia de "esquerda" não é mais referência suficiente para o engajamento político. Por isso, o artigo busca compreender a nova forma de compromisso político que o educador e o intelectual em geral precisam praticar, dizendo, por exemplo, que é preciso resgatar o valor da dúvida como método; compreender o processo de amadurecimento da cultura democrática; voltar a refletir sobre o próprio conceito de política "desinteressada" e reafirmar que todo ato pedagógico em si já possui uma implícita dimensão ético-política, questionando, assim, a vinculação burocrática com os partidos.

Palavras-chave: Memória e educação. Política e educação. Competência técnica e compromisso político. Conjuntura atual.

\section{Political ENGAgEMENT AND TECHNiCAL COMPETENCE: TWENTY YEARS LATER}

ABSTRACT: This article re-reads the debate occurred in the 80's regarding the relation among the educator's political engagement and his technical competence. It points out that the most emancipated

\footnotetext{
* Professor titular de filosofia da educação do Departamento de Educação, da Universidade Federal de São Carlos (UFSCAR). E-mail: nosellap@terra.com.br
}

Educ. Soc., Campinas, vol. 26, n. 90, p. 223-238, Jan./Abr. 2005 
ideas (as those divulged in Antonio Gramsci's texts) took the Brazilian pedagogical ideas into its dimension of political engagement, contributing inclusive, to electoral victory of the Laborer's Part. However, if at that time a certain "gramscian trendy" movement was reference and synonym to the most emancipated and free ideas; today considering the complex and multifaceted political reality it is necessary to deepen the reading of this author's ideas. A diffuse ideology of the "left wing" is no more a sufficient reference to the political engagement. For this reason this article tries to understand the new form of political engagement that the educator and the intellectual in general need to practice, saying for example that it is necessary to redeem the value of the doubt as a method; to understand the process of maturation of the democratic culture; to think again on the real process of "uninterested" politic and reaffirm that all pedagogical act in itself has already an implicit ethic political dimension, questioning thus, the bureaucratic linking with the parties.

Key words: Memory and education. Politic and education. Technical competence and political engagement. Present conjuncture.

\section{Relembrando os anos oitenta}

$S$

e a história é um garimpo, a memória é a bateia que revolve o cascalho do passado e busca dados preciosos para continuar nossa luta.

Vinte anos atrás, em 1983, fervia entre os educadores o debate sobre o compromisso político e a competência técnica. Polemizava-se contra a dicotomia entre o educador-político e o educador-técnico. A conjuntura política foi a oportunidade para a explosão daquele debate: os governos militares, que estavam sendo forçados a passar o poder aos civis, haviam enfatizado a dimensão tecnológica, as competências específicas e a prática do ensino como treinamento; ao contrário, a emergente democracia destacava o sentido e a necessidade do engajamento político da prática científico-pedagógica.

Em outras palavras: na década de 1980, de um lado estavam os defensores da neutralidade técnica do fazer pedagógico, do lado oposto entrincheiravam-se os defensores de um compromisso político inerente a quaisquer atividades pedagógicas. $\mathrm{O}$ debate acentuou-se 
por ocasião da publicação do livro da professora (e minha colega) Guiomar Namo de Mello (Magistério de $1^{\circ}$ grau - da competência técnica ao compromisso político, São Paulo: Cortez/Autores Associados, 1982). "Vejo [escrevera Guiomar] na capacitação profissional o ponto crítico a partir do qual imprimir um caráter político à prática docente" (idem, ibid., p. 146).

No mês de maio do ano seguinte (1983), a revista Educação \& Sociedade, n. 14, publicava um pequeno artigo de minha autoria: "Compromisso político como horizonte da competência técnica", no qual tecia algumas críticas à tese de Guiomar que operava, dizia eu, uma justaposição entre o ato técnico da prática pedagógica e seu engajamento político, considerando-os dois momentos seqüenciais e, portanto, separados: "A competência técnica não é uma categoria em si, universal, acima dos interesses de classe, mas, pelo contrário, competência e/ou incompetência são qualificações atribuídas no interior de uma visão de cultura historicamente determinada, pois existe o competente e o incompetente para certa concepção de cultura, como existe o competente e o incompetente para uma nova concepção de cultura" (Nosella, ibid, p. 92).

Distinguia eu, portanto, duas concepçôes fundamentais de cultura: a enciclopédica (burguesa) e a histórica (proletária), frisando que, tanto no âmbito da primeira quanto no âmbito da segunda, registramse ilustres competências pedagógicas. Por isso, não poderia existir, por exemplo, uma técnica de alfabetização, universal, neutra e prévia à opção política do alfabetizador.

Esse debate, como disse, alastrou-se entre os educadores dos anos de 1980 praticamente no Brasil inteiro. Hoje, reconheço que o nefasto taticismo político-partidário insuflava a polêmica que acabou gerando "uma imagem equivocada nos leitores [escreveu então o professor Dermeval Saviani] pois criou a idéia de que o autor da crítica (Nosella) desautorizava o autor criticado (Guiomar), colocando-se em campos opostos e definindo-se adversários renitentes" (Saviani, 1983, p. 112).

Com efeito, jamais desautorizei a colega e exímia educadora Guiomar Namo de Mello. Saviani percebera, com inigualável perspicácia, que à base da polêmica existia o equívoco do "vínculo entre neutralidade e objetividade" (idem, ibid., p. 137). O que fazer? Todo mundo sabe que os anos de 1980 foram marcados por muito roman- 
tismo político e por uma notável indulgência ao taticismo. Mas a história não flui em linha reta, feliz ou infelizmente.

Saldo daquele debate

Aquele romantismo político trouxe, felizmente, um inegável saldo positivo para o país e, especificamente, para o campo da educação.

Teoricamente, o debate dos educadores encontrou nos escritos de Antonio Gramsci um grande alento. Presenciamos a uma verdadeira "gramscimania", isto é, a uma excepcional difusão dos escritos desse intelectual marxista italiano. Calcula-se que mais de $40 \%$ das dissertações e teses de pós-graduação em educação, produzidas na década, citavam Gramsci como principal referência teórica. Suas frases eram citadas, em epígrafe, nos projetos ou nas propostas de política educacional de várias secretarias de Educação, estaduais e municipais. O nome de Gramsci era citado com grande freqüência nos congressos e nas reuniōes das várias associações científicas e sindicais dos educadores. A literatura sobre ele e dele era sempre bem-vinda e até mesmo bem vendida.

O primeiro saldo positivo decorrente dessa onda de estudos marxistas, sobretudo da visão gramsciana, foi o abandono por parte dos educadores do velho marxismo ortodoxo stalinista e a adoção sistemática da crítica ao tradicional didatismo técnico. Privilegiou-se a visão teórica que explica o fenômeno escolar pela sua relação com a sociedade, com a economia e com a política. O discurso repleto de citações gramscianas era, para os educadores de duas décadas passadas, elemento de distinção cultural que os prestigiava com relação aos tradicionais pedagogos didatistas. Gramsci e também Paulo Freire tornaram-se bandeiras de orgulho e estímulo para a organização político-sindical dos pedagogos.

Observe-se, também, que durante esses anos de transição do autoritarismo militar para a democracia ganhou relevância o termo "educador", sobrepondo-se ao de "professor", justamente porque "educador" semanticamente explicitava a necessidade do engajamento ético-político dos professores. Com efeito, o conceito de educador transcende o de professor. Este se refere às competências específicas adquiridas por uma pessoa, que as transmite a outras, ensinando-as e treinando-as. Aquele se refere à responsabilidade na formação integral do cidadão, à cumplicidade radical entre educando e educador. $\mathrm{O}$ pro- 
fessor que não assume plenamente a função de educador e se exime de sua responsabilidade de ensinar a leitura do mundo, para restringir-se à leitura das palavras - utilizando expressões freireanas -, era considerado um técnico asséptico, reducionista, que reeditava na prática pedagógica a velha tese da neutralidade científica.

Enfim: durante os anos de 1980, o pensamento pedagógico modernizou-se, arejou-se ao assumir sua dimensão de engajamento político. Novos conceitos e novas perspectivas teórico-práticas enriqueceram os debates no campo da educação, em que com muita freqüência se utilizavam termos e conceitos até então desconhecidos, como: sociedade civil e política - hegemonia - ideologia e contra-ideologia - intelectuais orgânicos e tradicionais - a educação como ato político-partidário educação e cidadania etc. Mais ainda: politicamente, a maioria dos educadores dos anos de 1980, sabedora de que a escola não se explica por ela própria e sim pela relação política que ela mantém com a sociedade, lutou para colocar na administração educacional partidos e homens compromissados com os objetivos da escola popular e libertadora. Até mesmo redutos tradicionalmente mais fechados, como os dos especialistas da educação (orientadores educacionais, administradores ou gestores, supervisores, diretores etc.), foram influenciados pela idéia de $\mathrm{o}$ ato pedagógico ser ao mesmo tempo um ato de compromisso político. Nos congressos da área (nacionais, estaduais, regionais e municipais), os especialistas da educação afirmavam que a relação pedagógicocientífica era fundamentalmente uma relação de hegemonia política. Assim, instigavam professores a buscarem uma forma de relação profissional que fosse ao mesmo tempo uma nova relação hegemônico-política, isto é, a hegemonia da classe trabalhadora.

Como vimos, esse movimento político dos educadores, ao longo destes últimos 20 anos, engrossou o movimento político nacional que desaguou nas vitórias eleitorais do Partido dos Trabalhadores, nos estados, nos municípios e, hoje, na federação.

\section{E hoje, qual compromisso político?}

Se na década de 1980 os educadores afirmaram que toda competência técnico-pedagógica era ao mesmo tempo um ato político (Damasceno et al., 1988), duas décadas depois, isto é, no complexo quadro po- 
lítico atual, é preciso reformular a pergunta: De que compromisso político e de que competência pedagógica estamos falando? Naquela época, quando marchávamos pelas ruas das nossas cidades manifestando-nos contra os governos militares, talvez pela urgência e pela ardência do momento político, afirmávamos apenas genericamente que a política e a técnica se imbricavam. Mas não chegamos a precisar a natureza específica dessa relação: não sentimos ainda a necessidade histórica de aprofundarmos teoricamente a forma dessa integração.

O educador de hoje, concretamente, como poderá exercer seu engajamento político e sua competência técnica? A difusa (e confusa) ideologia cognominada "de esquerda" não é mais referência suficiente. Por 20 anos caminhamos seguros guiados por um cometa brilhante no céu. Para nós todos, a distinção entre direita e esquerda era clara e insofismável. As dúvidas levantadas por certos intelectuais pareciam-nos impertinentes. Mas, de repente, assim como aconteceu quando os reis magos chegaram a Belém, a estrela, referência e guia, desaparece no breu da política atual. Por isso, hoje, torna-se urgente formular as perguntas: Por onde continuar o caminho? De qual compromisso político se trata?

\section{Pedagogia da dúvida}

Em primeiro lugar, precisamos voltar a valorizar a dúvida e a pergunta como método, mesmo que para alguns pareça isso impertinência. $\mathrm{O}$ poder estabelecido tem medo das perguntas, das dúvidas. Os poderosos preferem as afirmaçōes bombásticas, sem réplicas e sem tréplicas. Preferem as metáforas às entrevistas abertas, os discursos préfabricados ao diálogo ao vivo. Preferem as frases forjadas pela indústria cultural, pelos marqueteiros que não admitem dúvidas. Preferem frases peremptórias, absolutas, fechadas, autoritárias. Foi assim durante os regimes militares com o lema "Ame-o ou deixe-o". Será assim, também hoje, com o lema: "A esperança venceu o medo"? É preciso ter a coragem de perguntar: Mas o medo de quem? A atual tarefa política prioritária do intelectual, do educador é recolocar perguntas, voltar a valorizar as dúvidas:

A prática da ciência [diz Brecht na peça $A$ vida de Galileu] me parece exigir notável coragem, pois ela negocia com o saber obtido através da dúvida (...). 
Ela procura fazer com que todos duvidem (...). O nosso recurso novo, a dúvida, encantou o grande público (...). A luta pela mensuração do céu foi ganha através da dúvida. (Brecht, 1973, p. 161)

Foi este o sentido que pretendi dar ao meu livro, cujo título é uma interrogação: "Qual compromisso político?”. Isto é, como realizar o sonho socialista? Vale a pena comprometer-se com este governo menino incoerente, pirracento, déspota, que abandonou o ideário igualitário?

\section{Cultura democrática}

Em segundo lugar, considero que a fusão do compromisso político com a competência técnica, no momento, significa compreender o quadro político em que se vive jamais como um quadro avulso e separado do contexto histórico geral, mas como um momento de um processo demorado, de amadurecimento de uma profunda e sólida cultura democrática. Com efeito, regimes políticos fazem-se e desfazem-se em pouco tempo, até mesmo em poucos dias ou horas, mas uma cultura cria-se e solidifica-se ao longo de muitas décadas, isto é, por "tempos longos", utilizando uma expressão cara ao saudoso Milton Santos.

No Brasil já existiram regimes democráticos, mas uma cultura democrática, sólida e duradoura, é fruto de um ininterrupto processo histórico que infelizmente aqui faltou. Cultura democrática é um clima espiritual, inicialmente rarefeito, que com o passar dos anos, no respeito indiscutível às regras democráticas, que valoriza o processo e não só os resultados, que prioriza uma política econômica de inclusão e equilíbrio social, torna-se um senso comum denso, firme, quase um inconsciente coletivo. A cultura democrática não deixa espaço para os que se consideram donos da verdade, para os que temem as dúvidas e as divergências, para os que indefinidamente consideram inacabada a sua "tarefa histórica de exercício do poder", para os que encaram o poder não como "verbo" e sim como "substantivo".

Infelizmente, a cultura democrática está ainda longe de ser consolidada entre nós. Em todo caso, o processo foi desencadeado, existe, é promissor e não pode ser ameaçado, nem mesmo pelos que se consideram o ponto zero da História. Um processo democrático, inin- 
terrupto e longo, ao criar uma cultura democrática, eleva o grau da transparência social, socializa as regras do jogo democrático, populariza as leis fundamentais da economia nacional e internacional. Uma cultura democrática enterra, definitivamente, nossa tradicional cultura autoritária e escravocrata.

Especificamente, para o campo educacional, esse processo de produção de cultura democrática ainda é um “jovenzinho” de 20 anos, trouxe conquistas bem concretas, difundiu a escolarização, sobretudo a fundamental, testou novos processos de avaliação, viu florescer numerosas organizações sindicais e profissionais, animou grandes e vigorosos debates, produziu revistas, livros e comunicação virtual. Tudo isso contribuiu para a melhor identificação histórica do Brasil em geral e de seus educadores em particular. Entretanto, nossa frágil cultura democrática precisa de guardiōes e defensores contra toda tentação de recorrer a formas autoritárias e totalitárias do poder. Produzir e defender esse tipo de cultura é ser um educador tecnicamente competente e politicamente compromissado.

\section{Natureza da política}

Em terceiro lugar, para integrar a dimensão técnica e o compromisso político, precisamos voltar a meditar sobre o próprio conceito de política, sua natureza, revisitando a fundamentação teórica do poder político: Decorre este da definição dos seus fins ou dos seus meios?

Idealisticamente, política refere-se aos fins. Por isso, classicamente, diz-se que a política objetiva a ordem e a felicidade geral da cidade ou da nação. Mas é a questão dos meios que, conforme advertem Maquiavel e Marx, põem-nos no caminho (método) mais concreto e fecundo para nossas análises. Vista pela ótica dos meios, a política é essencialmente poder ou domínio, o qual, por sua vez, distingue-se em três grandes âmbitos: o poder econômico, o poder ideológico e o poder político propriamente dito ou de governo (ver N. Bobbio, Dicionário de Política, verbete homônimo).

$\mathrm{O}$ poder econômico utiliza-se da força dos bens necessários à sobrevivência humana; o ideológico utiliza-se da força das idéias e dos símbolos para vencer as mentes e dobrar a vontade dos homens; o de 
governo utiliza-se da força física e burocrática que lhe competem legítima e exclusivamente.

Assim posta a questão, perguntamo-nos: O compromisso político do educador situa-se no âmbito do poder econômico, do ideológico (espiritual) ou do burocrático-militar? São esferas interligadas, todavia, prática e conceitualmente, são distintas. A resposta a esta questão é óbvia: o educador exerce seu compromisso político essencialmente no âmbito do poder ideológico ou espiritual.

\section{Reler Gramsci}

Para justificar adequadamente esta resposta, precisamos reler Gramsci, com maior atenção e menos apressadamente de como foi lido nos anos de 1980. Se naqueles anos compreendemos corretamente a função e a natureza dos intelectuais afirmando seu inevitável comprometimento com alguma classe social fundamental, equivocamo-nos quando entendemos que necessariamente todos os intelectuais orgânicos seriam progressistas, de esquerda, ao passo que os tradicionais seriam conservadores, de direita. Uma leitura mais aprofundada de Gramsci diz-nos outra coisa. Quando ele assumiu a direção do Partido Comunista Italiano, em 1923, chama logo a atenção do partido para a necessidade de se interessar mais pelos intelectuais tradicionais e de cuidar melhor destes. Foi ele, então, que pela primeira vez na história da militância política do socialismo trouxe para o primeiro plano a figura e a importância política do intelectual tradicional: "A formação dos intelectuais tradicionais é o problema mais interessante" (Gramsci, 1975, p. 1.523).

Note-se que jamais pretendia Gramsci diminuir a importância dos intelectuais orgânicos, isto é, dos "funcionários" do partido. A função destes era indiscutível. Mas caberia, isso sim, retirar da sombra do esquecimento histórico a importância política do intelectual tradicional. O orgânico representava a espinha dorsal da instituição, mas o apoio do tradicional refletia seu viço, sua força vital e sua potencialidade futura. Os intelectuais tradicionais "se põem a si mesmos como autônomos e independentes do grupo social dominante. Esta autoposição não deixa de ter conseqüências de grande importância no campo ideológico e político" (idem, ibid., p. 1.515). 
Em suma, se autonomia no sentido de neutralidade científica, obviamente, não existe, é indispensável, entretanto, captar o sentido histórico do intelectual tradicional (clero, escritores, professores, filósofos etc.). Com efeito, a vinculação destes com a tradição científicoprofissional lhes confere um diferencial e um prestígio que se traduzem numa potencialidade política que o intelectual orgânico não possui. Trata-se da mesma força política da intelligentsia, indispensável para um partido vivo e pujante.

Não podemos interpretar essa valorização gramsciana dos intelectuais tradicionais como um mero uso político oportunista. Subjacente a isso existe um profundo respeito e amor à cultura desinteressada, à escola humanista clássica e à prática política profunda, séria, coerente e nãotaticista. Pela mesma razão, ele defende freqüentemente a necessidade de se produzir e se ler textos difíceis, quando o assunto é complexo, rejeitando textos panfletários e dissimuladores. Quando Gramsci chama a atenção do partido para o peso político que os intelectuais tradicionais possuem, expressa a visão epistemológica que rejeita tanto a neutralidade científica como o taticismo stalinista. Com essa posição se identifica a tese de Saviani que 20 anos atrás afirmava não existir "vínculo entre neutralidade e objetividade". A neutralidade é uma ideologia deformadora da realidade, a objetividade, ao contrário, é uma conquista que o homem alcança quando possui as condições técnicas adequadas e a liberdade de espírito.

Concluindo: reler Gramsci hoje torna-se indispensável para entendermos a nova forma de compromisso político que o educador e o intelectual em geral precisam praticar. Quão salutar seria, por exemplo, no quadro político em que vivemos, reler a carta que Gramsci escreveu do cárcere para sua mulher Júlia, na qual discute a noção de cultura desinteressada! Júlia receava que "desinteressado" significasse "neutro". Gramsci responde que "desinteressado" se contrapõe a oportunista, imediatista, utilitarista; à profissionalização precoce, reducionista, minimalista; a politiqueiro, taticista e eleitoreiro, como tantos projetos educacionais que bem conhecemos: "Os cientistas, em sua atividade, são desinteressados” (Gramsci, 1965, p. 598).

Forçar alguém a ser um militante de carteirinha, burocraticamente orgânico, pode simplesmente significar criar um desequilibrado, e isso é um desserviço à política no sentido "desinteressado", moderno, 
aberto, pleno. Gramsci afirmou que sua esposa Júlia adoeceu psicologicamente porque violentou suas inclinações artísticas (musicais) para se dedicar à militância política prática, ativista, tendo sido forçada moralmente a isso:

Cara Iulca (...) eu sempre acreditei que tua personalidade desenvolvia-se prioritariamente no âmbito das atividades artísticas, mas que tenha sofrido quase uma amputação por causa de uma orientação meramente prática e de interesses imediatos que deste à tua vida. Diria que em tua vida houve um erro "metafísico", que deixou seqüelas de desarmonia e desequilíbrios psicofísicos. (idem, ibid.).

O caso da esposa de Gramsci faz-nos pensar em inúmeros nomes de artistas, cientistas, escritores etc. etc. que, felizmente, não cometeram o mesmo "erro metafísico" e cuja obra revolucionou a história dos homens. Para citar um nome: Richard Wagner, que participou da revolução alemã de 1848 e dela foi testemunha. Observe-se, porém, que sua militância política de orientação meramente prática e de interesse imediato não contribuiu significativamente para a mudança da História. Entretanto, sua música, politicamente comprometida, revolucionou os valores e os costumes da sociedade burguesa. O mesmo pode-se dizer de Mozart, Beethoven, Verdi, Picasso, Tolstoi e de muitíssimos outros. Em todos esses "intelectuais tradicionais" se constata um elemento comum: não se submeteram incondicionalmente às exigências imediatistas do mercado. Seu trabalho respondia às exigências "desinteressadas" de sua criatividade e de sua competência técnica, isto é, de alguém que trabalha olhando para a História no horizonte longínquo. O mercado foi a eles, não eles ao mercado. Essa é a dimensão política proposta prioritariamente por Gramsci.

Portanto, reler Gramsci, hoje, é começar a entender que o compromisso político não se efetiva somente por uma militância orgânica, burocrática, ${ }^{1}$ justaposta ao ato técnico-pedagógico, porque o compromisso político se expressa na forma e no conteúdo do próprio ato pedagógico.

\section{Política "desinteressada”}

O que vem a ser uma prática política desinteressada? É a política que se livrou de três atávicos e mortíferos vícios: do taticismo po- 
lítico, do determinismo histórico-científico e do burocratismo autoritário.

a) O taticismo político é uma postura eleitoreira e imediatista. Clássico exemplo de taticismo político foi a defesa que muitos comunistas fizeram do stalinismo. De coração não concordavam com Stalin, mas era tático defendê-lo. Ora, o taticismo, na opinião de Gramsci, garante vitórias em curto prazo, mas prejudica os ideais socialistas no longo prazo. Foi por isso que, em 1926, condenou oficialmente a expulsão do Partido Comunista Russo de Trotski, Zinoviev e Kamenef. Mesmo não concordando com muitas teses desses companheiros, afirmava que: "A nova política econômica garante o pleno desenvolvimento da contradição. A unidade e a disciplina não podem ser mecânicas e impostas burocraticamente; devem ser leais e pela convicção" (Gramsci, 1971, p. 130).

A história do socialismo do século XX não trilhou o caminho traçado por Gramsci, mas o de Stalin. Os prejuízos decorrentes dessa política foram imensos. Luckács, em sua última entrevista, confessou que o taticismo político representou a ideologia das esquerdas do século XX. Por que, então, repetirmos hoje os mesmos erros?

b) O determinismo histórico-científico é caracterizado por uma política à base de planos e previsões mecânicas e dogmáticas que prevê o futuro a partir de um pobre etapismo histórico. Considera que a política do partido deve ser implementada até mesmo recorrendo à ditadura. $\mathrm{O}$ determinismo histórico não admite a possibilidade de errar; não se considera um momento de um processo e sim o começo absoluto da História.

c) O burocratismo autoritário reflete o desespero do poder quando os ideais esmaeceram ou foram esquecidos. Em outubro de 1926, Togliatti solicitou o apoio do Partido Comunista Italiano (e dos demais partidos comunistas nacionais) ao autoritarismo stalinista. Gramsci respondeu: "O teu raciocínio está todo viciado de burocratismo” (Gramsci, 1971, p. 136).

\section{Partido ético}

Gramsci, infelizmente, morreu em 1937, vítima da política autoritária de Stalin e do taticismo político de seu "amigo" Togliatti, comunistas que não "quiseram" libertá-lo do cárcere fascista. Sua cunhada Tatiana, que o assistiu nos últimos dias de vida, afirmou que Gramsci "sussurrava" que a forma política para sair da triste e trágica 
história da década de 1930 era "ultrapassar a militância burocrática através de uma verdadeira militância ética, porque acima do partido político há sempre o partido ético" (Nosella, 2002, p. 43).

Hoje, quando se defende que alguém deve votar no sentido contrário à sua consciência individual, porque assim o centralismo burocrático determinou, uma reflexão mais profunda sobre o partido burocrático e o partido ético torna-se indispensável.

O partido ético reúne os homens que não desistem de sonhar a utopia da justiça e da liberdade universais e, ao mesmo tempo, sabem que seu limite prático é fixado pela dialética entre consciência individual e sociedade civil e política; mas sabem também que a consciência individual é sempre a última instância de sua decisão. Ora, o partido ético abre espaço à dialética dos diferentes, sabe permanecer na esfera da liberdade sem se aprisionar na esfera da natureza (burocracia).

\section{Competência técnico-pedagógica}

A competência profissional, quando resultado de pesquisa sem preconceitos, profunda, socialmente benéfica, historicamente avançada, efetua de per si uma forma de compromisso político até mesmo superior ao compromisso burocrático administrativo. Por exemplo: a força política de pesquisas de Galileu, de Vigotsky, de Einstein, não decorria de alguma vinculação burocrático-partidária e sim de sua excelência científico-técnica, pois beneficiavam a sociedade como um todo: "O fato de adquirir autoridade por meio do estudo deu-me uma terrível responsabilidade política" (Einstein, Revista Pesquisa Fapesp, n. 79, p. 88).

Assim, o educador, para se comprometer politicamente, não precisa, a rigor, de outra carteirinha além de seu diploma de professor, nem precisa de outras atividades militantes para além de suas atividades pedagógicas.

Disse que não precisa de carteirinha partidária. Precisou no passado. Hoje, a carteirinha de partido para um educador é uma possibilidade e um valor, não é mais uma necessidade, porque o ato pedagógico em si já possui uma implícita dimensão ético-política.

Nesta perspectiva e concluindo: Quais as características do ato pedagógico de um professor comprometido politicamente nesta sociedade do século XXI? 
Em síntese: ele precisa ensinar a produzir, a criar coisas novas, não apenas a comercializar. Precisa ensinar também a priorizar o valor de uso e não apenas o valor de troca. Precisa ainda defender a escola como um sistema permanente, orgânico, cujos efeitos positivos são de longo alcance, superando a necessidade dos projetos especiais de caráter político-eleitoral. Até mesmo a alfabetização não pode mais ser comparada como campanha. Precisa entender e ensinar que a sociedade pós-industrial e virtual em que vive produz ampla margem de tempo livre, que pode tornar-se um tempo de desemprego ou de criatividade, de vazio ou de liberdade, de destruição ou de preservação, de barbárie ou de solidariedade.

Um educador competente e politicamente compromissado ensina os alunos que, se a escola do passado (séculos XIX e XX) qualificou exescravos e migrantes para a cidadania industrial, a escola do século XXI precisa preparar ex-trabalhadores industriais para a nova cidadania pósindustrial e virtual, criando novas formas de distribuição de riquezas além dos tradicionais salários; repropondo para o currículo o clássico paradigma da totalidade: educar à filosofia e à técnica, à criatividade e à disciplina, à meditação e às atividades profissionais práticas.

O homem, numa era planetária caracterizada por uma explosão técnica sem precedentes, é submetido a uma acelerada tempestade de informações e imagens. A consciência humana, como um espelho fragmentado, encontra seriíssimas dificuldades para se recompor à luz de um princípio pedagógico unitário. $\mathrm{O}$ espaço humano é fragmentado, banalizado ou até mesmo destruído. As pessoas, quando tentam se encontrar e se autocentrar, esbarram em fragmentos de filmes e documentários, em imagens fortes e autoritárias que ofuscam sua realidade e escamoteiam a fragilidade cotidiana.

Encontrar homens para além das ilusões dessas imagens e integrar suas atividades de produção e de prazer é o grande desafio atual da educação. Mas isso não é resultado mecânico do mundo técnico, das máquinas. É fruto exclusivo da interioridade e disciplina humanas. Só no cadinho incandescente da consciência, as informações, à luz do projeto elaborado pelo sujeito, podem educar. Se a mecânica se encarrega cada vez mais dos trabalhos fadigosos, a escola precisa encarregar-se de ensinar ao homem como comandar as máquinas e como usufruir solidariamente os bens da vida.

Recebido em abril de 2004 e aprovado em agosto de 2005. 


\section{Nota}

1. O termo "orgânico", em seu sentido ampliado, pode significar um envolvimento profundo, eficiente e explícito, para além do sentido estrito de "funcionário" que aqui utilizamos. Nesse sentido, a expressão "orgânico" subsume a expressão "tradicional", conotando apenas "profundidade e adequação". Neste caso, desaparece a distinção entre "tradicional" e "orgânico”.

Referências bibliográficas.

BRECHT, B. A vida de Galileu. Rio de Janeiro: Civilização Brasileira, 1973.

A CRÍTICA da razão pura. Pesquisa Fapesp, São Paulo, n. 79, p. 88, set. 2002.

DAMASCENO, A. et. al. A educação como ato político partidário. São Paulo: Cortez, 1988.

FREIRE, P. Pedagogia dos sonhos possiveis. São Paulo: UNESP, 2001.

GRAMSCI, A. Letere del carcere. Torino: Einaudi, 1965.

GRAMSCI, A. La construzione del Partido Comunista. Torino: Einaudi, 1971. p. 130.

GRAMSCI, A. Caderno do cárcere n.12. Torino: Einauidi, 1975.

MELLO, G.N. Magistério de $1^{\circ}$ grau: da competência técnica ao compromisso político. São Paulo: Cortez; Campinas: Autores Associados, 1982.

NOSELLA, P. Compromisso político como horizonte da competência técnica. Educação \& Sociedade, São Paulo, n.14, p. 91-97, 1983.

NOSELlA, P. A escola de Gramsci. Porto Alegre: Artes Médicas, 1992.

NOSELLA, P. Gramsci e os educadores brasileiros. In: Nosella, P. Qual compromisso político?: ensaios sobre a educação brasileira pós-ditadura. 2. ed. rev. e ampl. Bragança Paulista: Universidade São Francisco, 2002. 
Compromisso político e competência técnica: 20 anos depois

POlitiCA. In: Bobbio, N. et. al. Dizionario di politica. Milano: UTET, 1990.

SAVIANI, D. Competência política e compromisso técnico ou (o pomo da discórdia e o fruto proibido). Educação \& Sociedade, São Paulo, n. 15, p. $111-143,1983$. 